\title{
Synoptic patterns leading to hailstorm in Chaharmahal and Bakhtiari province, Iran
}

\author{
Bromand Salahi $^{1, *}$, Ahmad Nohegar ${ }^{2}$, Mahmoud Behrouzi $^{3}$ and Mehdi Aalijahan ${ }^{1}$ \\ ${ }^{1}$ Department of Physical Geography, University of Mohaghegh Ardabili, Ardabil, Iran. \\ ${ }^{2}$ Faculty of Environment, University of Tehran, Tehran, Iran. \\ ${ }^{3}$ Institute of Grape, University of Malayer, Malayer, Iran. \\ *Corresponding author. e-mail: bromand416@yahoo.com
}

MS received 22 November 2016; revised 19 July 2017; accepted 23 July 2017; published online 6 March 2018

The purpose of this study was to extract the synoptic patterns of $500 \mathrm{mb}$ geopotential height and the sea level pressure leading to form hail in Chaharmahal and Bakhtiari province, Iran. To this end, at first, we explored hail occurrence in different areas of the province under investigation. Then, using sea level pressure and $500 \mathrm{mb}$ geopotential height data, the patterns of hail occurrence were investigated through hierarchical clustering and Ward's method. The level of $500 \mathrm{mb}$ patterns resulting in hail formation in the area include: (1) settlement of a cut-off low pressure blocking in Turkey and Iran's position in downstream of trough and injection of humidity coming from the Red Sea; (2) settlement of low ridge in northern Europe and Iran lying in downstream of the trough and injection of humidity of the Mediterranean Sea; (3) settlement of a cut-off low pressure in east of Europe and Iran lying in downstream of the trough; and (4) settlement of a deep trough in the Mediterranean Sea, formation of an omega-shaped blocking in Northern Europe and Iran lying in downstream of the trough. At sea level, the following patterns have caused hail formation in Chaharmahal and Bakhtiari province: (1) settlement of low pressure in Iran and Russia accompanying high pressure in Taklimakan Desert and east of Europe; (2) settlement of low pressure in Iran and high pressure in Egypt, northern Europe, and Taklimakan Desert; and (3) settlement of low pressure in Iran, Saudi Arabia and south of Italy and high pressure in Egypt and Siberia.

Keywords. Synoptic patterns; hierarchical clustering; hail; Chaharmahal and Bakhtiari province.

\section{Introduction}

Extreme rising of air flow accompanied by electrical phenomena brings about hail. The diameter of a hailstone ranges from 5 to $50 \mathrm{~mm}$ and sometimes even more. The intensive growing of the hail is due to vertical movements of air in the cumulonimbus clouds. Hot and humid weather at the lower levels of the atmosphere, rising cumulus clouds with extreme cold accompanied by continuously changing weather conditions are the requirements for hail formation.

Hail is one of the climatically devastating disasters whose damage is notable on various economic sectors (Saa Requejo et al. 2011). Its damage on agriculture sector in China was more than one billion dollars in 2004. Hail has damaged a vast area of cotton production in Arizona State of America. 
From 1948 to 2009, in Pinal and Maricopa, on average, hail caused damage in cotton fields about 504716 and $415787 \$$, respectively.

Hail occurrence has different time and place variables and it takes place more in mountainous areas than the other places. The study of geographical distribution of damaged areas deriving from hail shows that the areas apt to hail in Cyprus (Michaelides et al. 2008) and Iran (Lashkary et al. 2015), lie in mountainous regions. With respect to time, there is a variety of hail occurrences in different geographical places (Chantraket et al. 2015).

Researchers such as Vinet (2001) and Giaiotti et al. (2003) believe that existence of topography, presence of water vapour in the atmosphere, and rapid air warming are important factors in hail occurrence. Sioutas and Flocas (2003) carried out analyzing synoptic hail formation in north of Greece and reported that the highest frequency of hail is the time that west wind waves accompany the trough. Buckley et al. (2003) analyzed Sydney hailstorm of April 14, 1999 using instability indices and synoptic maps. With regard to the phenomenon, they noted the role of water vapour, warming the earth's surface, and the low pressure. Merino et al. (2013) simulated hailstorm in a 100day period in southeastern Europe and analyzed the hail using $500 \mathrm{mb}$ synoptic maps and instability indices.

Evan et al. (2016) studied hailstorm in Colorado using precipitable water, radar data, and synoptic analysis. Nisi et al. (2016) analyzed spatial and temporal distribution of hailstorms in the Alpine region from statistical and synoptic perspectives. Sioutas and Flocas (2003) analyzed days with hail in a period of 26 years (1976-2001) in northern Greece and extracted and analyzed synoptic patterns caused by hail in that area. They found that short wave trough was the most important factor in creating hail in that area. On a 12-year period (2002-2013), hail occurrence in Switzerland was studied by Schemm et al. (2016). They concluded that the occurrence of hail in Switzerland is related to the existence of cold front at $700 \mathrm{mb}$ level of the atmosphere. Li et al. (2016) studied hail occurrence using reanalyzed data from NCEP-NCAR from 1960 to 2012 in central China. They studied atmospheric circulation patterns which led to hail and concluded that five synoptic patterns resulted in hail occurrence in the country. These patterns were deep trough at 500 and $850 \mathrm{mb}$ and thermal low pressure at sea level.
Using the average of sea level pressure and $500 \mathrm{mb}$ geopotential height of the atmosphere, Aran et al. (2011) clustered and classified synoptic patterns causing hail in Lleida (Catalonia). Researchers such as Simeonov and Giorgiev (2003), Garcia-Ortega et al. (2007), Beck et al. (2008), Kunz et al. (2009), Philipp and Bartholy (2010), Twardosz (2010), Saa Requejo et al. (2011), Johnson and Sugden (2014) and Wapler and James (2014) have classified atmospheric patterns leading to hail based on cluster analysis and identified and analyzed hail causing atmospheric patterns. Also, workers such as Brooks et al. (2003), Kunz and Puskeiler (2010), Mohr and Kunz (2013), Allen and Karoly (2014), Merino et al. (2014), Cica et al. (2015), Mohr et al. (2015) and Schemm et al. (2016) have studied hailstorms and thunderstorms in their researches.

Chaharmahal and Bakhtiari province examined in this study, as located in the highlands of central Zagros Mountains, is the pass way of different air masses and has the necessary potential for hail formation. Every year this event leads to huge losses in this region. Therefore, if we can identify synoptic patterns that cause hail formation, environmental planners will be able to offer preventive strategies to counter this phenomenon in order to remove or reduce the damages. So, the atmospheric patterns of $500 \mathrm{mb}$ level and patterns of sea level have been determined and analyzed in this research in Chaharmahal and Bakhtiari province because they are the main causes of hailstorm.

\section{Materials and methods}

Chaharmahal and Bakhtiari province with an area of $16,532 \mathrm{~km}^{2}$, lies between $31^{\circ} 9^{\prime}-32^{\circ} 48^{\prime} \mathrm{N}$ and $49^{\circ} 28^{\prime}-51^{\circ} 25^{\prime} \mathrm{E}$ in Iran (figure 1). In this research, in order to extract the synoptic patterns of hail formation, at first, hail occurrences in a 10-year period (2000-2009) were taken from the synoptic stations of Chaharmahal and Bakhtiari province (Kohrang, Shahr-e Kord, Lordegan, and Brujen). After initial screening, the codes related to the hail occurrences in the area were identified for 53 days in which hailstorm had occurred. Then, the data related to the sea level pressure and $500 \mathrm{mb}$ geopotential heights were taken from the website of the National Center for Environmental Prediction (NCEP) for modeling and extraction of sea level and upper atmospheric patterns. 


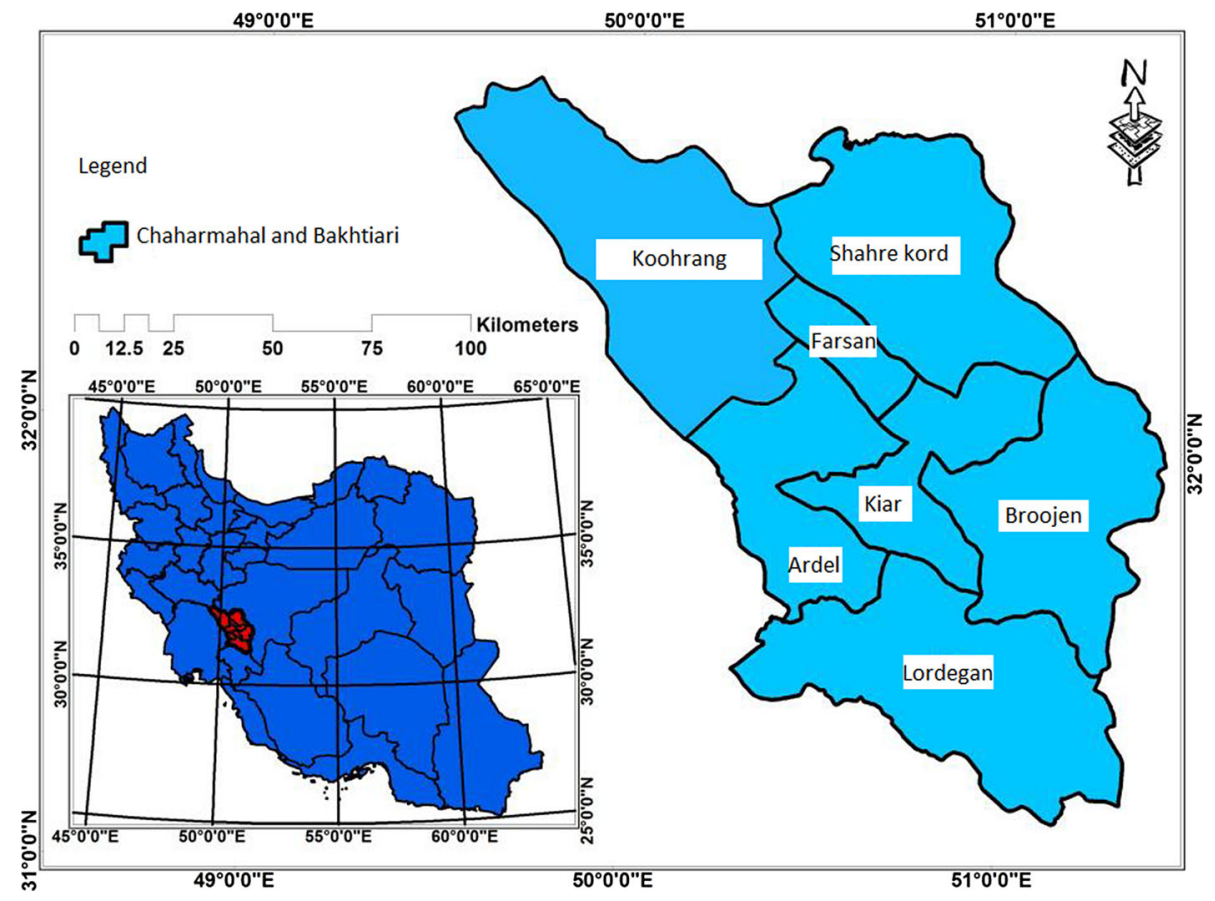

Figure 1. Geographical location of Chaharmahal and Bakhtiari province.

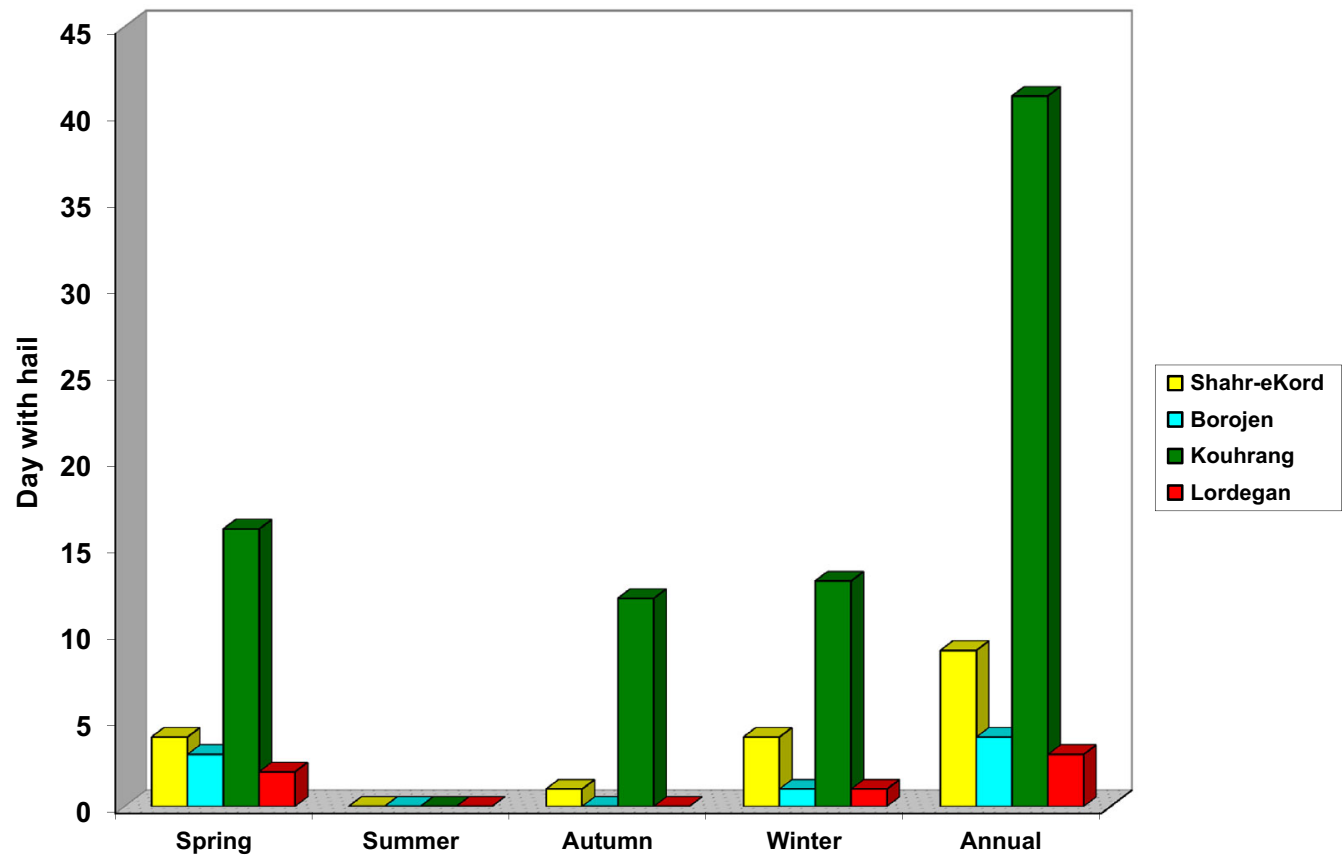

Figure 2. Seasonal hail occurrence in Chaharmahal and Bakhtiari province.

Different hierarchical clustering methods were tested to classify and extract the sea level and 500 $\mathrm{mb}$ geopotential height patterns, and finally, the Ward's clustering method with Euclidean distance was identified as the best method the results of which are reflected in the present research. The Ward's method purpose in each step of clustering is to find the least square error increases within the group in two clusters that are merged together. Total square error within groups $v_{T}(K)$ at one point with the groups of $K$, and the variable $j$ by having $N_{i}$ and the elements in each of the groups are defined as follows (Hervada-Salaa and JarautaBragulat 2004) 


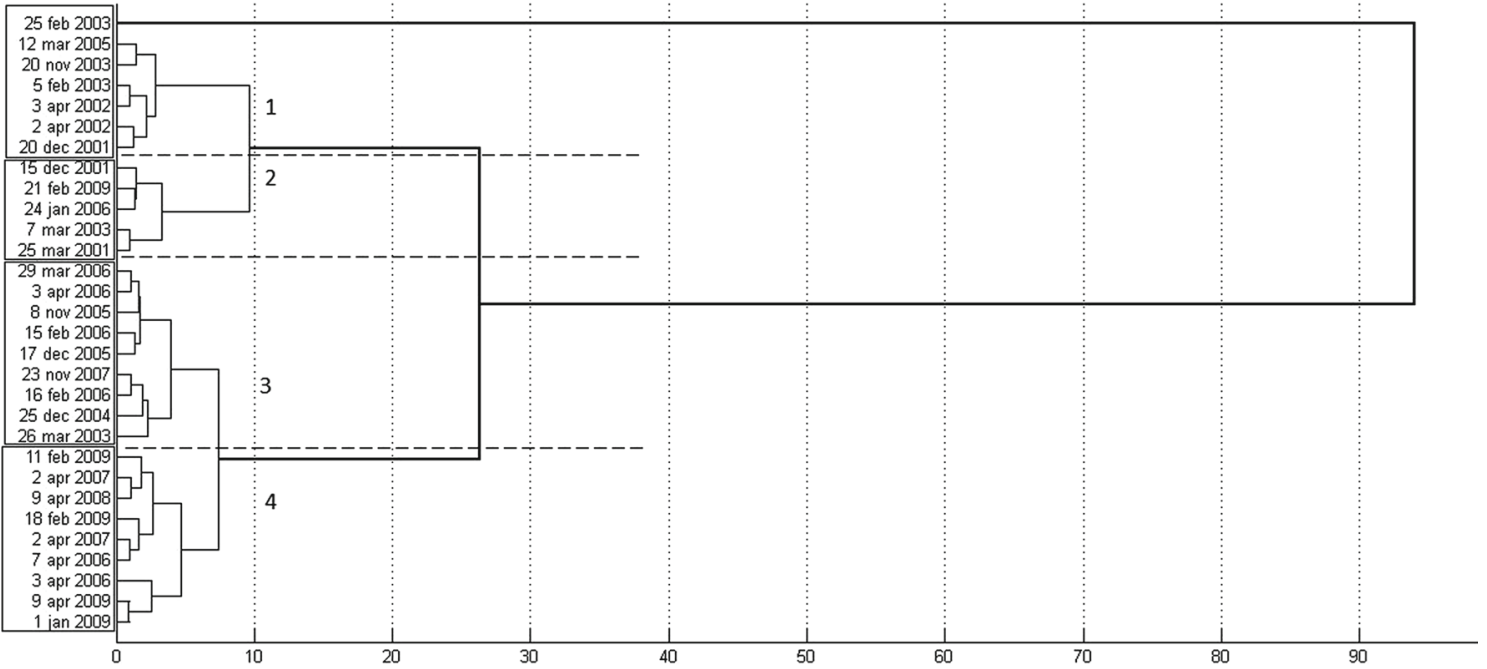

Figure 3. Dendrogram for $500 \mathrm{mb}$ geopotential height.

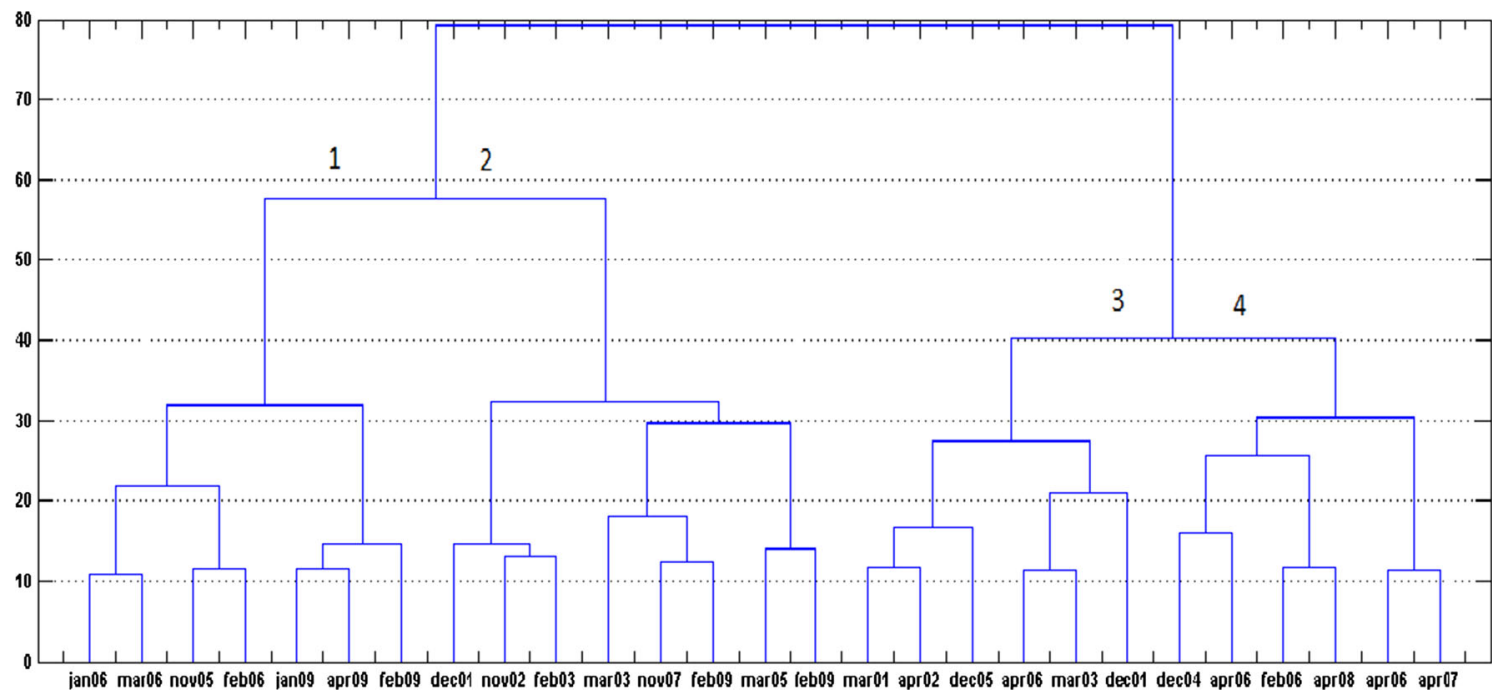

Figure 4. Dendrogram for sea level pressure.

$$
\begin{aligned}
& v_{T}(K)=\sum_{k=1}^{K}\left(\sum_{j=1}^{J}\left(\sum_{i=1}^{N_{i}}\left(\left(x_{i j k}-\bar{x}_{j k}(i)\right)^{2}\right)\right)\right) \\
& \bar{x}_{j k}(i)=\frac{1}{N_{i}} \sum_{i=1}^{N_{i}} x_{i j k} ; \sum_{i=1}^{K} N_{i}=N
\end{aligned}
$$

Euclidean distance between $Z_{i}$ and $Z_{j}$ can be obtained through the following equation

$$
\begin{gathered}
d_{M}^{2}\left(Z_{i}, Z_{j}\right)=\left(Z_{i}-Z_{j}\right)^{T} C^{-1}\left(Z_{i}-Z_{j}\right) \\
C=\frac{1}{N} \sum_{i=1}^{N}\left(Z_{i}-\bar{Z}\right)\left(Z_{i}-\bar{Z}\right)^{T}, \\
i, j=1,2, \ldots, N .
\end{gathered}
$$

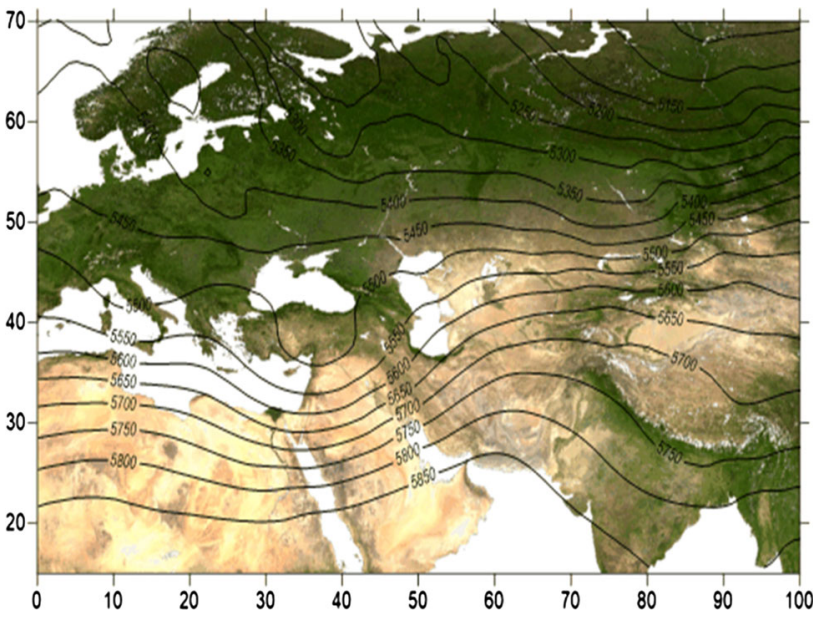

Figure 5. $500 \mathrm{mb}$ geopotential height. 

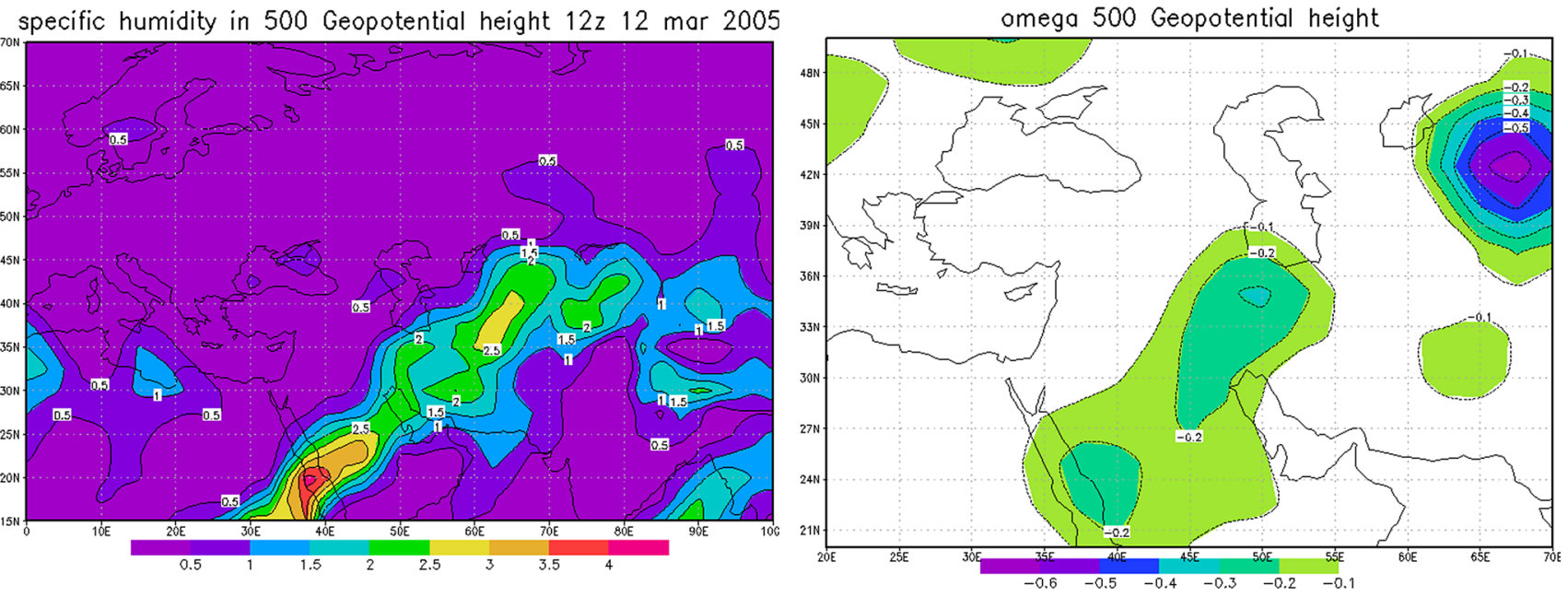

Figure 6. Specific humidity and omega at $500 \mathrm{mb}$ geopotential height for $12 \mathrm{March}, 2005$.

In this formula, $\bar{Z}$ is the mean. In each step, two clusters with the least number of variables are merged together. To draw the map of the patterns, at first, the maps were changed to numerical data through Grads software and transferred to the Surfer software after clustering, and finally, its average was calculated by Kriging method, and then the maps were drawn. In order to analyze the instability of the weather in the hail occurrence days in the study area and examine the special humidity and omega of the atmosphere, one day was selected and analyzed as the index day, which had correlation with the extracted pattern from any sea level pressure and $500 \mathrm{mb}$ geopotential height pattern. The sixth kind of Hovmoller graph was used for absolute humidity, in which time and latitude are fixed but longitude and atmospheric levels are variable.

\section{Results and discussion}

Figure 2 shows the seasonal hail occurrence in Chaharmahal and Bakhtiari province. Over the year, the maximum level of hail has occurred in spring, autumn, and winter, respectively. Hail occurrence has not been recorded in summer. Figures 3 and 4 show the dendrogram of $500 \mathrm{mb}$ of geopotential height and sea level pressure. With respect to the results from hierarchical clustering analysis and Ward's method, the days under study are divided into four clusters in the two data types of geopotential height and sea level pressure. Extracted clusters could effectively justify the atmospheric patterns leading to hail formation.

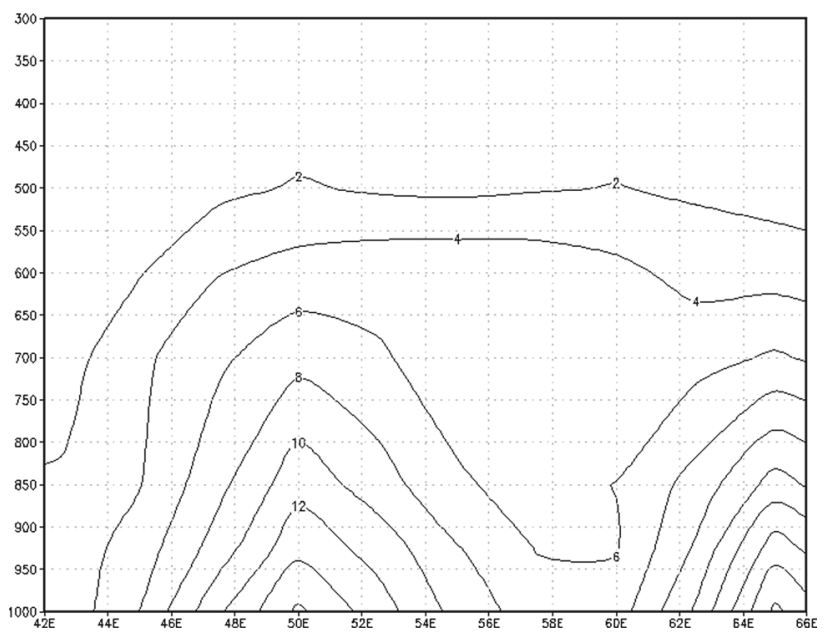

Figure 7. The sixth kind of Hovmoller graph.

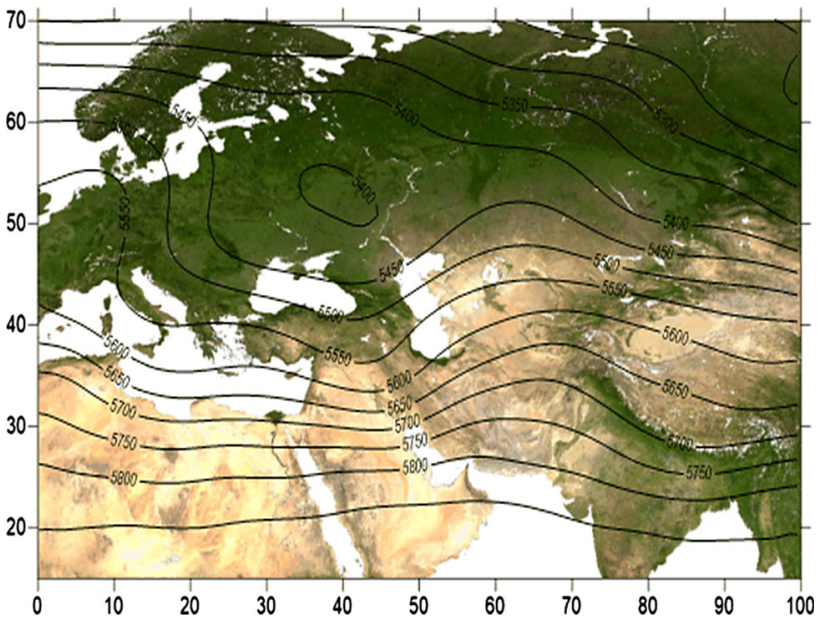

Figure 8. $500 \mathrm{mb}$ geopotential height.

\subsection{Pattern 1: Geopotential height at $500 \mathrm{mb}$ level}

In this pattern (figure 5), cut-off low over Turkey is emerged with $5500 \mathrm{~m}$ height leading to deviation of 
specific humidity in 500 Geopotential height $12 z 25$ mar 2001
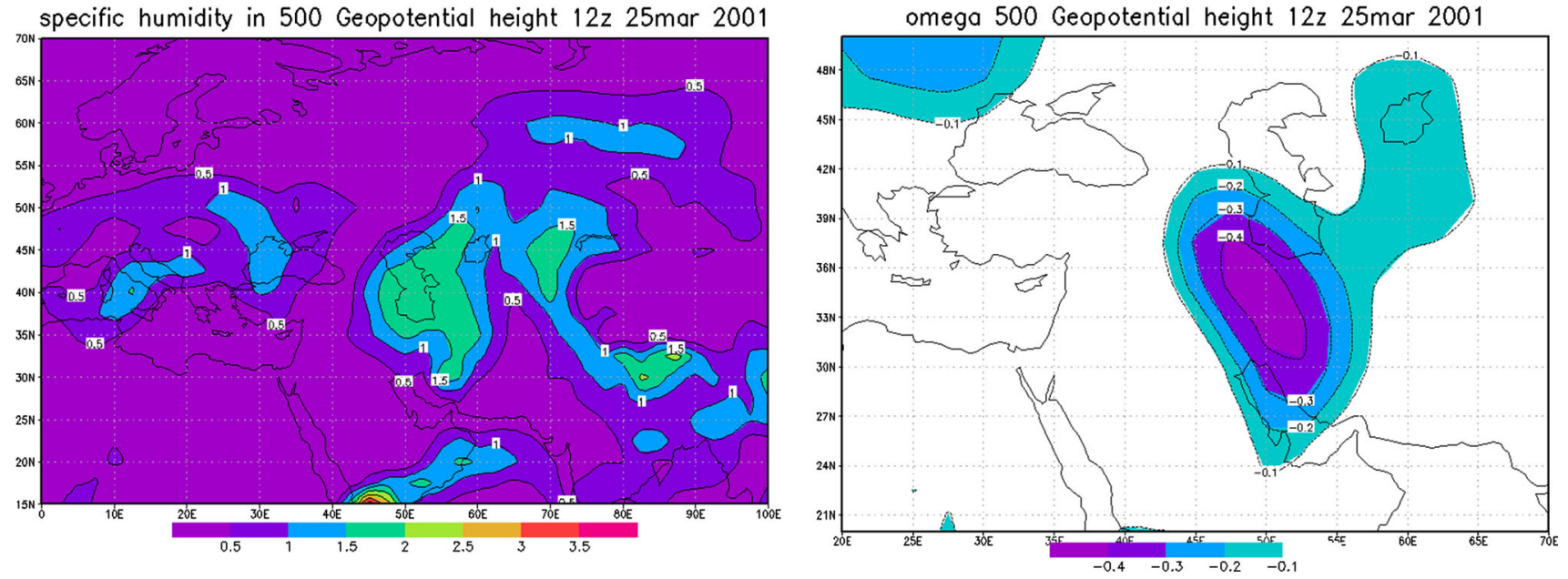

Figure 9. Specific humidity and omega at $500 \mathrm{mb}$ geopotential height for 25 March, 2001.

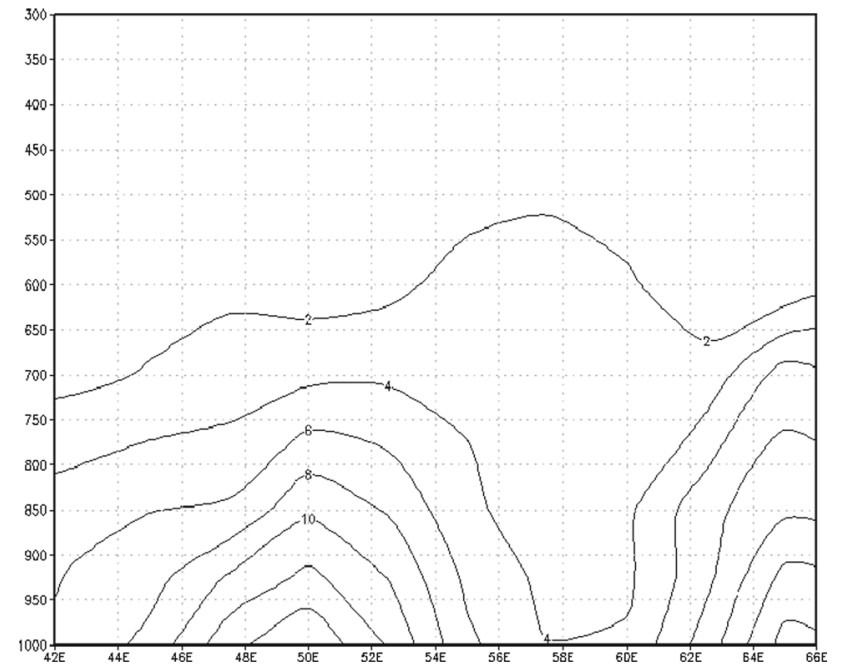

Figure 10. The sixth kind of Hovmoller graph.

westerly winds wave from zonal mode to meridinal mode and has created a deep trough, which is extended to the Red Sea. The study area was far from the created instability through cut-off low but it has been affected by the created trough. Being located in the east of the respective trough has caused cyclonic movements and air ascending. In addition, westerly winds in their deepest place in the Red Sea have absorbed enough moisture and moved towards Iran and after clashing with Zagros Mountains and because of the existence of positive vorticity caused the rapid ascent of air in the mountains leading to hail occurrence in this region.

Due to the position of respective area in downstream of the Mediterranean trough, positive vorticity makes the atmosphere unstable and omega index will reach $-0.3 \mathrm{P} / \mathrm{s}$, which represents a vertical movement in the atmosphere of this region in Iran (figure 6). Specific humidity map of $500 \mathrm{mb}$

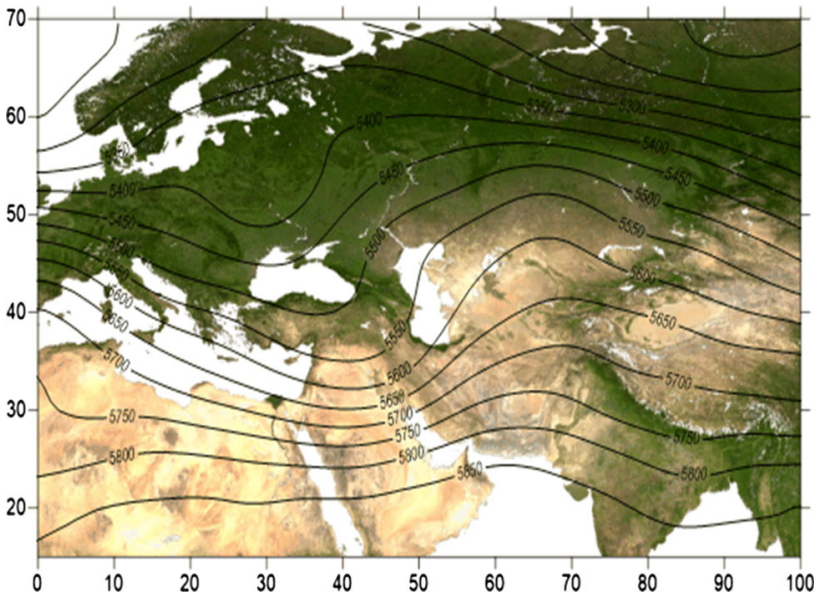

Figure 11. $500 \mathrm{mb}$ geopotential height.

level of the day shows that a strong humidity core is settled on the Red Sea. Also, the sixth type of Hovmoller graph (figure 7) indicates the existence of excellent moisture in the study area. This moisture has reached $16 \mathrm{~g}$ in the lower levels of the atmosphere. Settlement of jet stream core at $300 \mathrm{mb}$ level of the Caspian Sea has resulted in the instability of lower levels in the atmosphere. Westerly wind waves in the middle levels of the atmosphere leads to moisture absorption and transmission of moisture from the Red Sea to the respective area. This amount of moisture leads to instability for upward movements in the respective region and incidence of hail.

\subsection{Pattern 2: Geopotential height at $500 \mathrm{mb}$ level}

In this pattern (figure 8), a long and shallow trough was made in eastern Europe and led to the creation of cut-off low. In this trough, veer point of wave is in the west of Iran. In this pattern, 
specific humidity in 500 Geopotential height 00z 03apr 2006
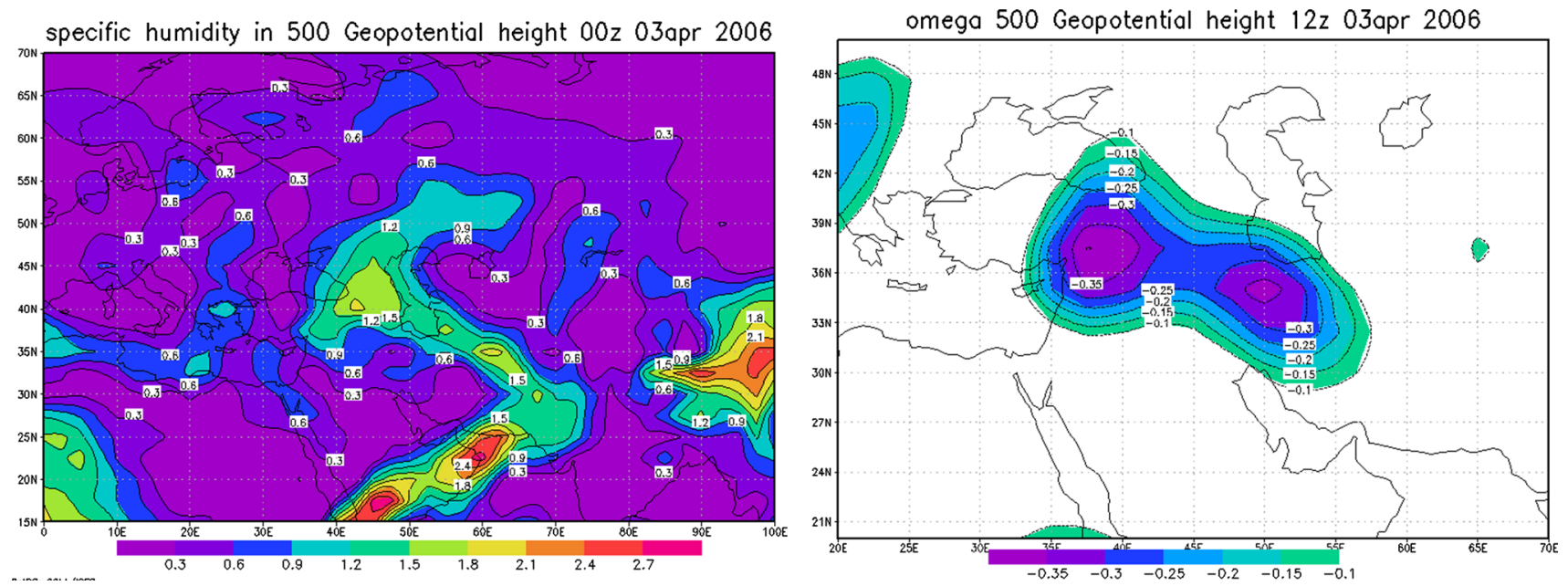

Figure 12. Specific humidity and omega at $500 \mathrm{mb}$ geopotential height for 3 April, 2006.

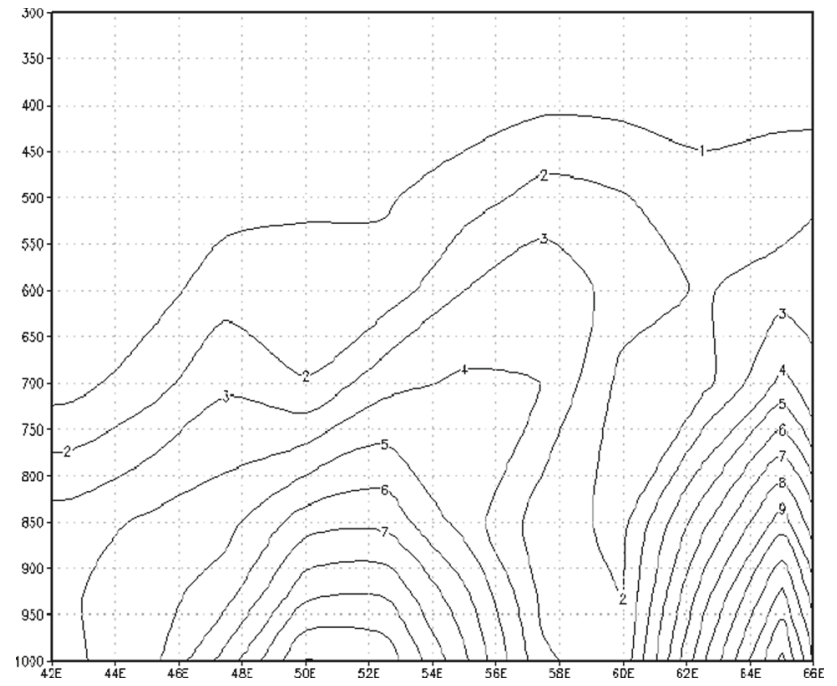

Figure 13. The sixth kind of Hovmoller graph.

Chaharmahal and Bakhtiari province has experienced unstable weather conditions. As the respective area is located in the east of the trough, which is considered the place of positive vorticity and anticlockwise movements of the air, the conditions are suitable for the ascendance of air. By the transition of westerly winds from the Mediterranean Sea, the required humidity for the supply of the ascended air is provided.

Checking the day's omega map in pattern 2 (figure 9), we can see that, on this day, Iran was in downstream of the Mediterranean deep trough, and it was along with the high level divergence and low level convergence. Numerical index of omega also proves this. On this day, at $300 \mathrm{mb}$ level, jet stream core was not observed in this region. Hovmoller graph (figure 10) shows that, in the 32nd parallel north, there was suitable moisture in the

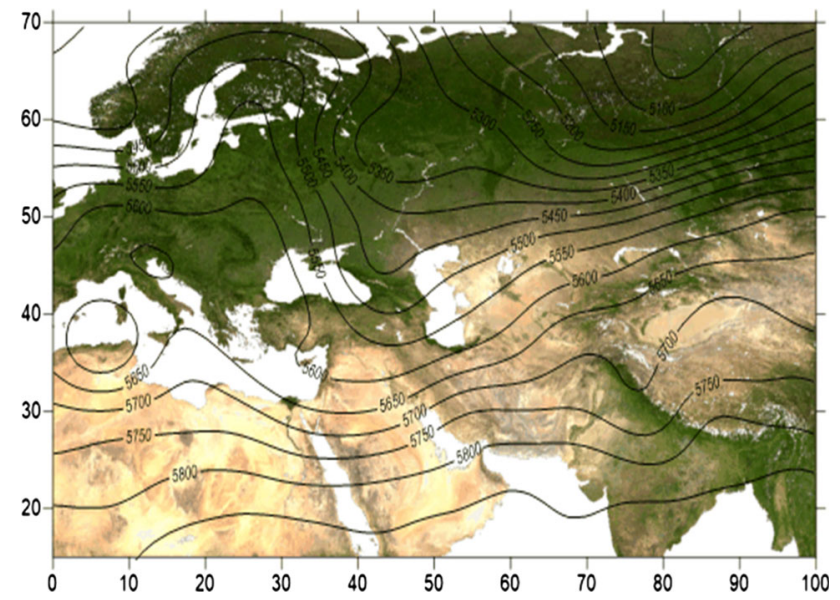

Figure 14. $500 \mathrm{mb}$ geopotential height.

respective area and it concentrated in the lower levels of the atmosphere. With regard to the direction and speed of westerly winds at this level of the atmosphere, moisture from the Mediterranean Sea has acted as thermodynamic energy to produce atmospheric instability and hail occurrence in the respective region.

\subsection{Pattern 3: Geopotential height at $500 \mathrm{mb}$ level}

In the third pattern (figure 11), on the eastern Europe, a cut-off low was created that led to the formation of a deep trough. The axis of this trough is northwest-southeast. In this atmospheric pattern, the study area is in downstream of the trough, which is the location of maximum positive vorticity. Cold air blowing from western Europe on the west of trough on the Mediterranean Sea caused the absorption of enough moisture from this resource and ultimately carried it to the east 
specific humidity in 500 Geopotential height $06 z 11$ feb 2009

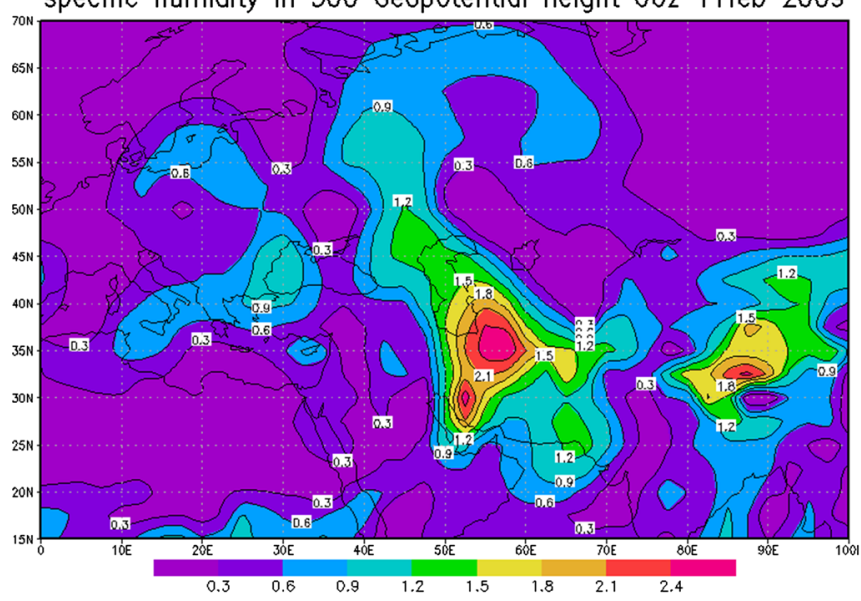

omega 500 Geopotential height $06 z 11 \mathrm{feb} 2009$

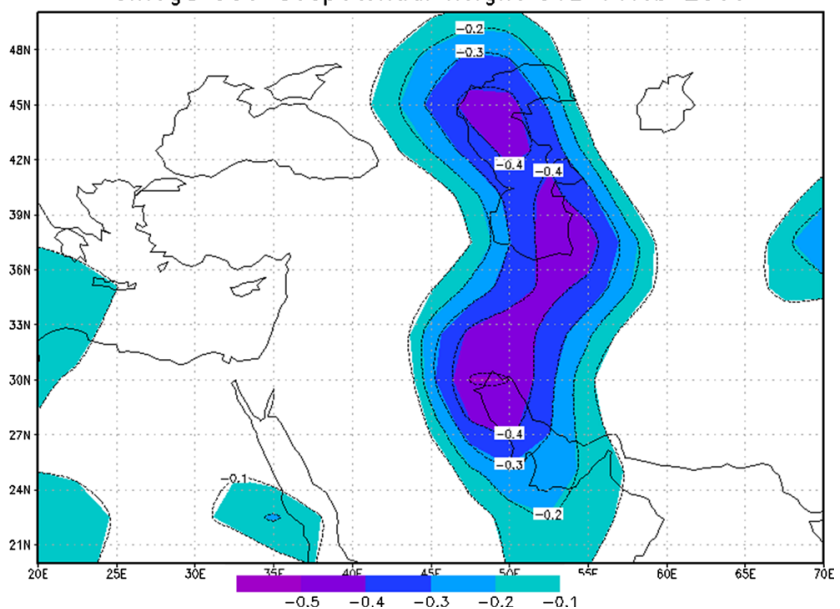

Figure 15. Specific humidity and omega at $500 \mathrm{mb}$ geopotential height for 11 February, 2009.

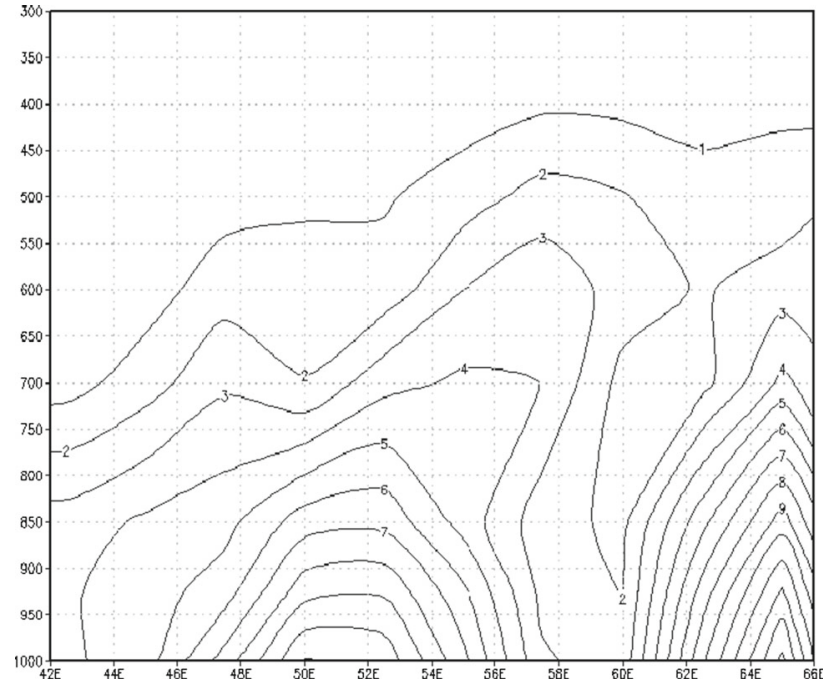

Figure 16. The sixth kind of Hovmoller graph.

of the trough and to the respective area, thus forming hail. Omega and special moisture rates in the third pattern indicated that, on this day, west of Iran and the respective area were in the east of the deep trough, which provided a condition for the ascendance of air over the atmosphere of the respective area (figure 12). At $300 \mathrm{mb}$ level, the speed of jet stream is $30 \mathrm{~m} / \mathrm{s}$, which covers the entire country and leads to the instability of the lower atmosphere. The omega rate at $500 \mathrm{mb}$ level, with numerical index of $-0.35 \mathrm{P} / \mathrm{s}$, in the west of Iran and east of the Mediterranean Sea, is the explanation for the instability and ascendance of air in the west of Iran and the respective area. The map of special moisture demonstrates the presence of moisture core in the northwest of Iran, which affects the respective area. Hovmoller graph (figure 13) also indicates the concentration of moisture

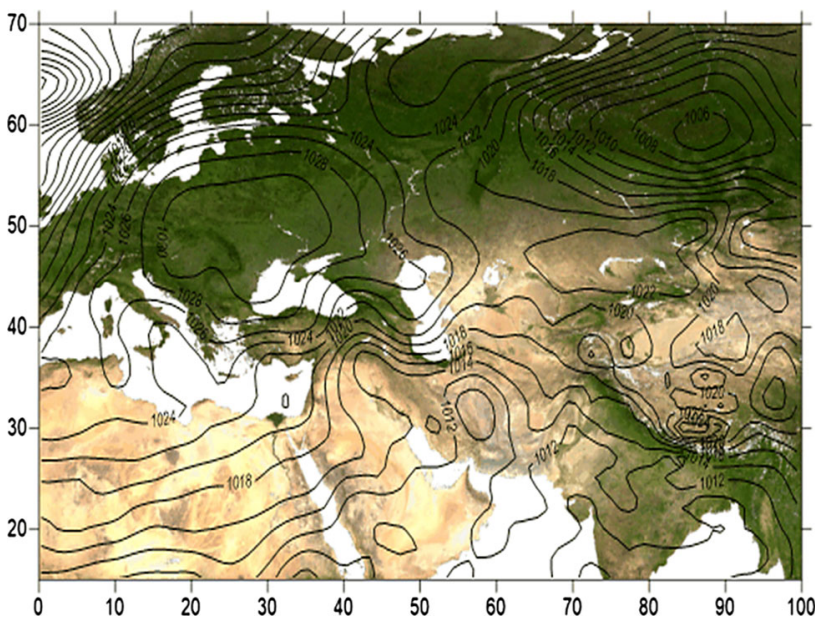

Figure 17. Pattern 1, sea level pressure.

in the lower levels of the respective area. All in all, these conditions have caused hail occurrence in the respective area.

\subsection{Pattern 4: Geopotential height at $500 \mathrm{mb}$ level}

In this pattern (figure 14), omega-shaped blocking was created in Europe and continued to Scandinavia. In the east of the respective blocking, cold weather from higher latitudes flows towards lower latitude and has caused the creation of a deep trough in the west of Europe. The study area is located in the east of the trough, which is the place of maximum ascendance flows and instability. In the west of the trough, cold air stream flew into the Mediterranean Sea from southern Europe, and by the absorption of moisture has moved to the west of Iran and the respective area, and after ascending from Zagros Mountains caused hail occurrence in Chaharmahal and Bakhtiari province. 

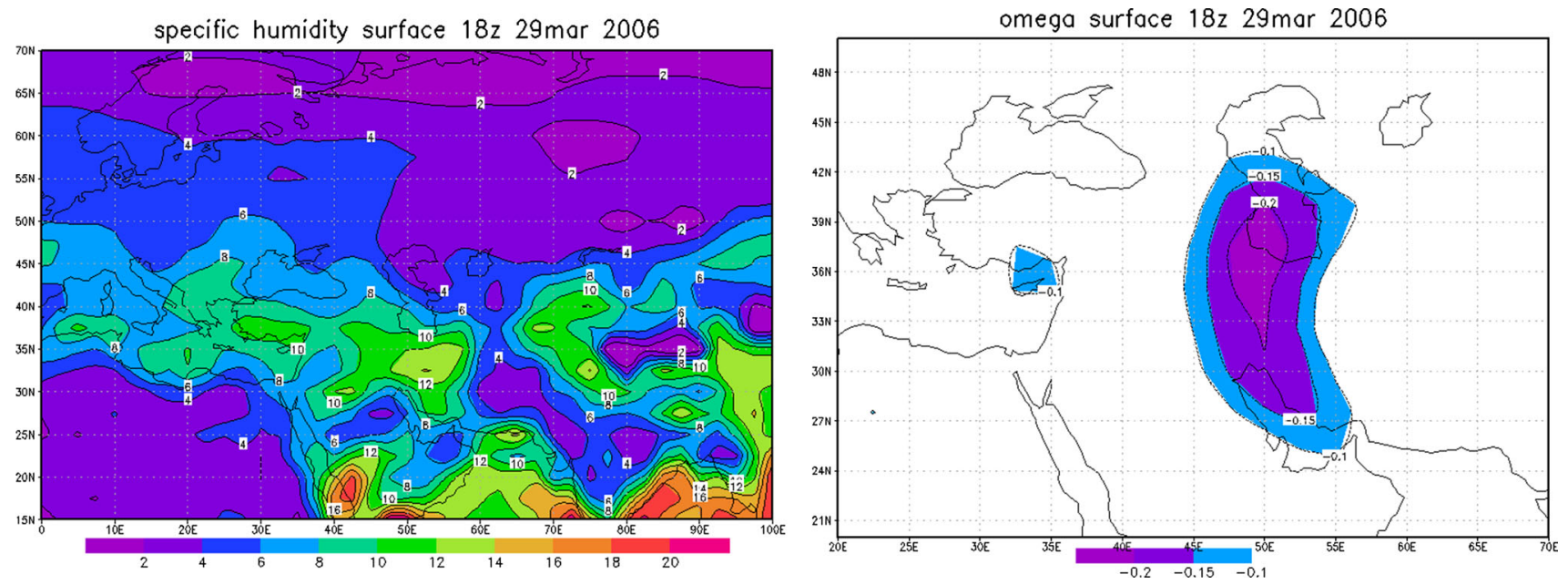

Figure 18. Specific humidity and Omega at $500 \mathrm{mb}$ geopotential height for 29 March, 2006.

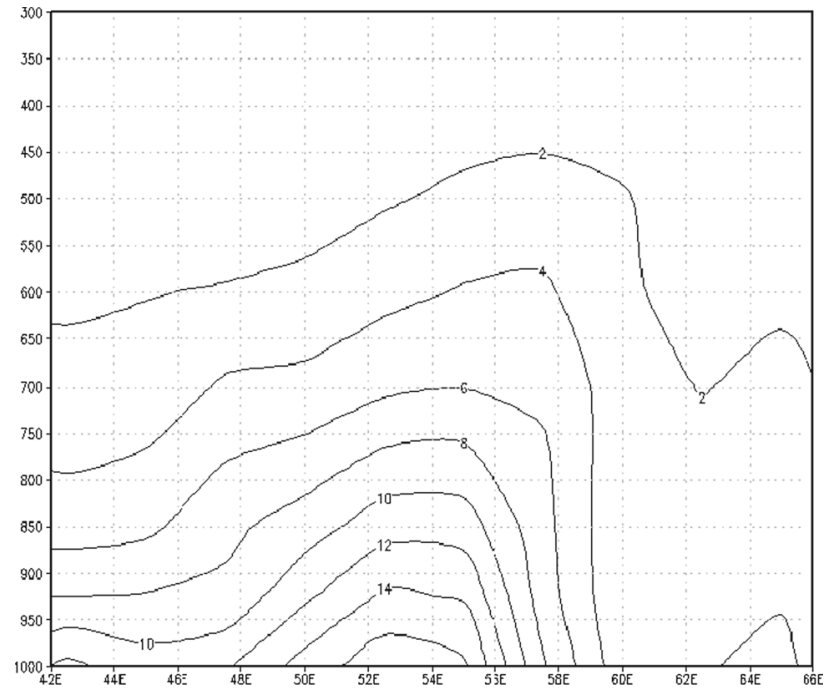

Figure 19. Pattern 1, sixth kind of Hovmoller graph.

This pattern of atmospheric blocking settlement in Europe has created a deep trough appearing in the east of the Mediterranean Sea and the west of Asia and finally carried the moisture of the Mediterranean Sea to Iran. Omega map (figure 15) refers to the existence of severe ascending movements in the atmosphere of Chaharmahal and Bakhtiari province. Investigation of jet stream in higher levels of atmosphere shows that jet stream core with the speed of $60 \mathrm{~m} / \mathrm{s}$ in the southwestern of Iran is the underlying cause of instability in the lower atmosphere. Hovmoller graph (figure 16) also refers to the investigation of strong humidity core, and up to $700 \mathrm{mb}$ level, enough humidity is present. The existence of strong humidity core over Iran and the study area indicates thermodynamic energy for the

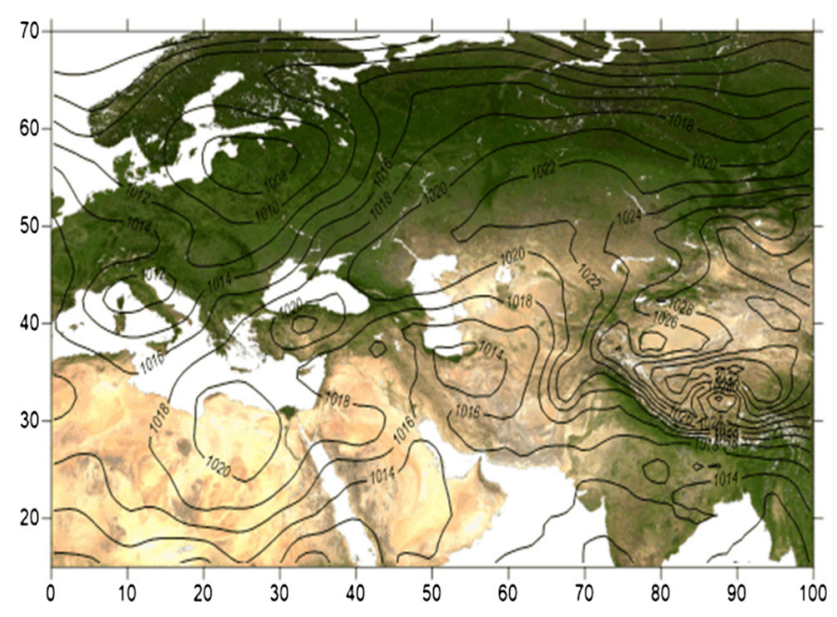

Figure 20. Pattern 2, sea level pressure.

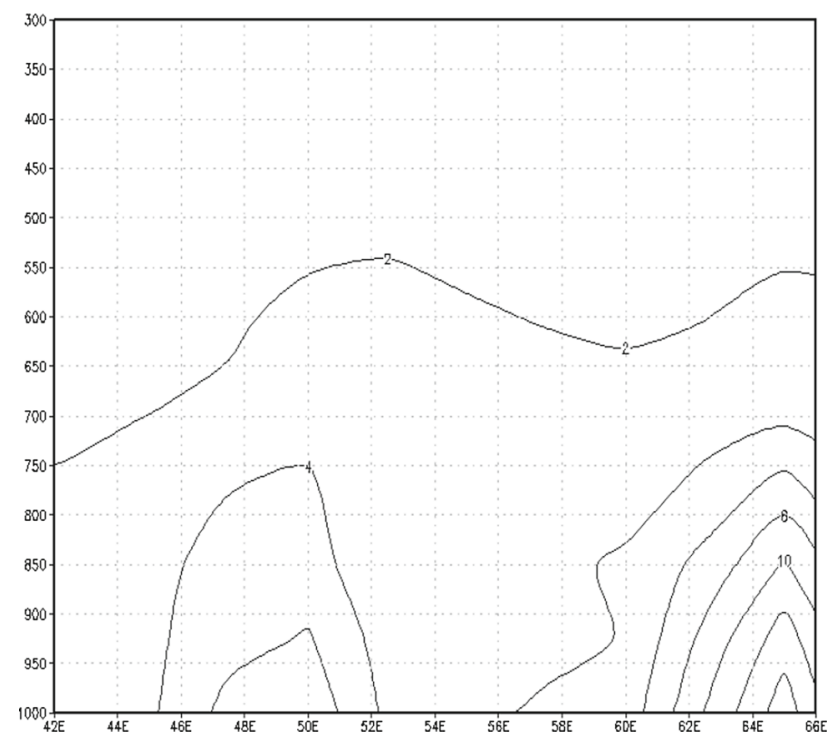

Figure 21. Pattern 2, sixth kind of Hovmoller graph. 

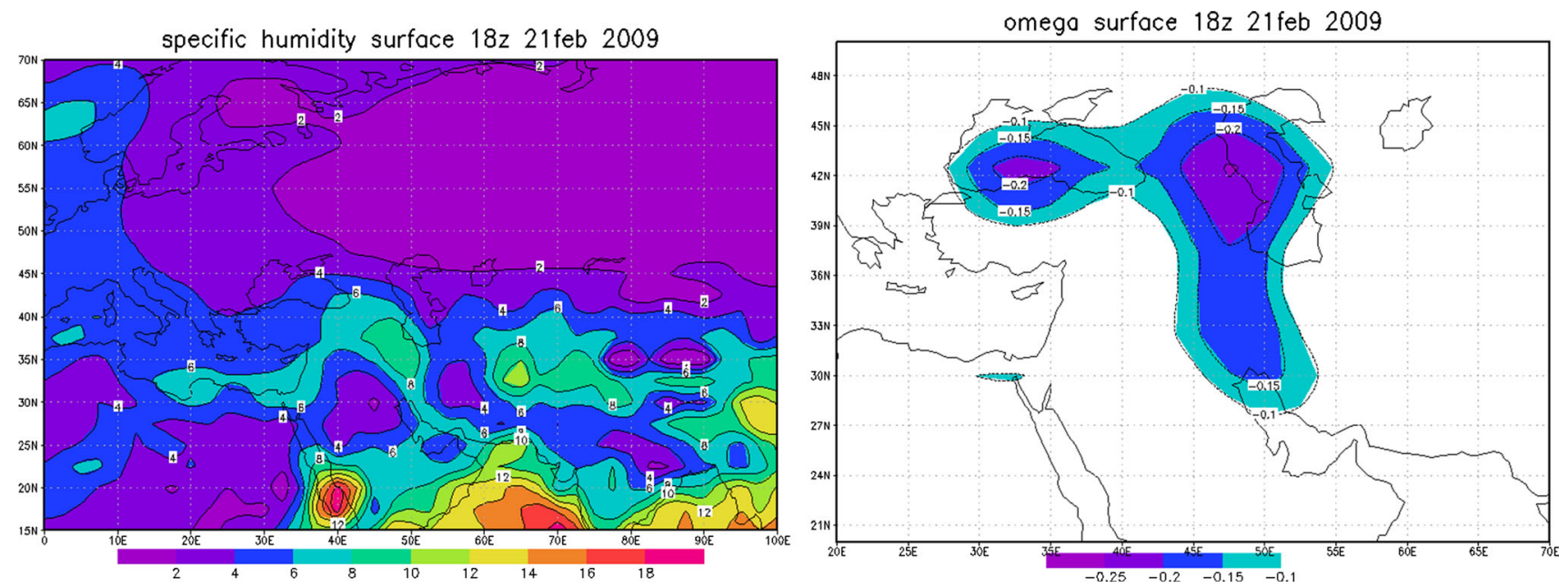

Figure 22. Specific humidity and omega at $500 \mathrm{mb}$ geopotential height for 21 February, 2009.

formation of cumulonimbus clouds and eventually hail occurrence.

\subsection{Pattern 1: Analysis of sea level pressure}

In the first pattern of the sea level pressure (figure 17), in central Iran, a low pressure system was composed of the central core pressure of 1010 $\mathrm{mb}$ and its tongue had embraced the whole part of the country. Also, a strong high pressure system was formed in the eastern Europe, and its east tongue had passed from the Caspian Sea and reached the Aral Sea. The center of low pressure with central core pressure of $1006 \mathrm{mb}$ was settled on Russia. Settlement of this pressure pattern had made the atmosphere of Iran and the respective area, unstable. The most important pressure system leading to hail occurrence in Chaharmahal and Bakhtiari Province was the created pressure gradient between the low pressure of central Iran and the high pressure of eastern Europe, which led to the transmission of cold air from Europe to lower latitudes and by collapsing with low pressure of Iran, led to the formation of a front. The omega map at $1000 \mathrm{mb}$ level (figure 18) shows, on this day, a strong core of negative omega was formed in the west of Iran representing the most upside movements and instability in the study area. Also, the index of specific humidity on the day shows that the maximum specific humidity was about $14 \mathrm{~g} / \mathrm{kg}$. This was the maximum value compared to the other parts of the country. Huff Moller graph (figure 19) also indicates concentration of humidity in the study area and it continued up to $700 \mathrm{mb}$ level. The resulted instability from these conditions can lead to the occurrence of hail in the study area.

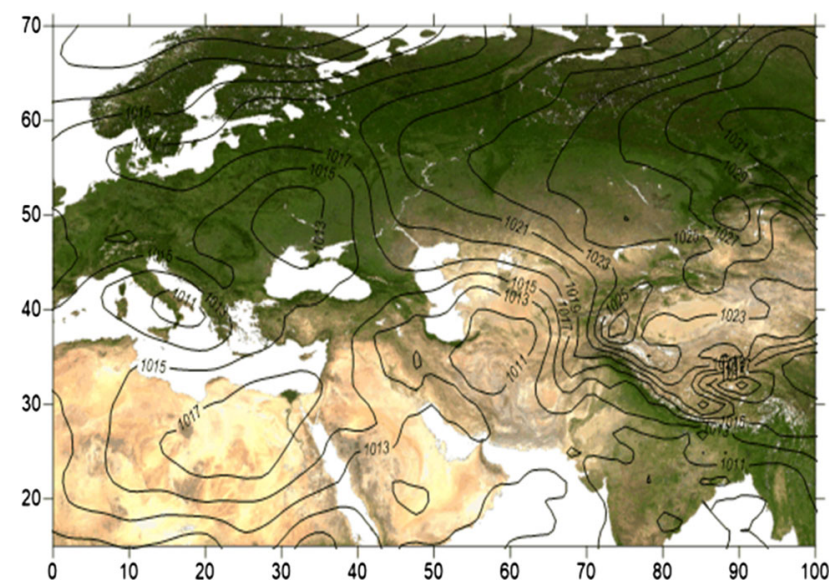

Figure 23. Pattern 3, sea level pressure.

\subsection{Pattern 2: Analysis of sea level pressure}

In the second pattern of sea level pressure (figure 20), a high pressure system with central core pressure of $1014 \mathrm{mb}$ settled on the atmosphere of Iran. Another high pressure system established over Egypt and its tongue extended to the east. Also, a low pressure system with central core pressure of $1008 \mathrm{mb}$ established over the northern Europe. In addition, a strong high pressure system settled over the Taklamakan desert in the west of China. Penetration of the tongues in both centers, from southwest (high pressure of Egypt) and the northeast (high pressure from the west of China) towards Iran, and the establishment of relatively low pressure system versus the listed high-pressure systems, led to the aggravation of convergence and unstable flows in the atmosphere followed by hail occurrence. 

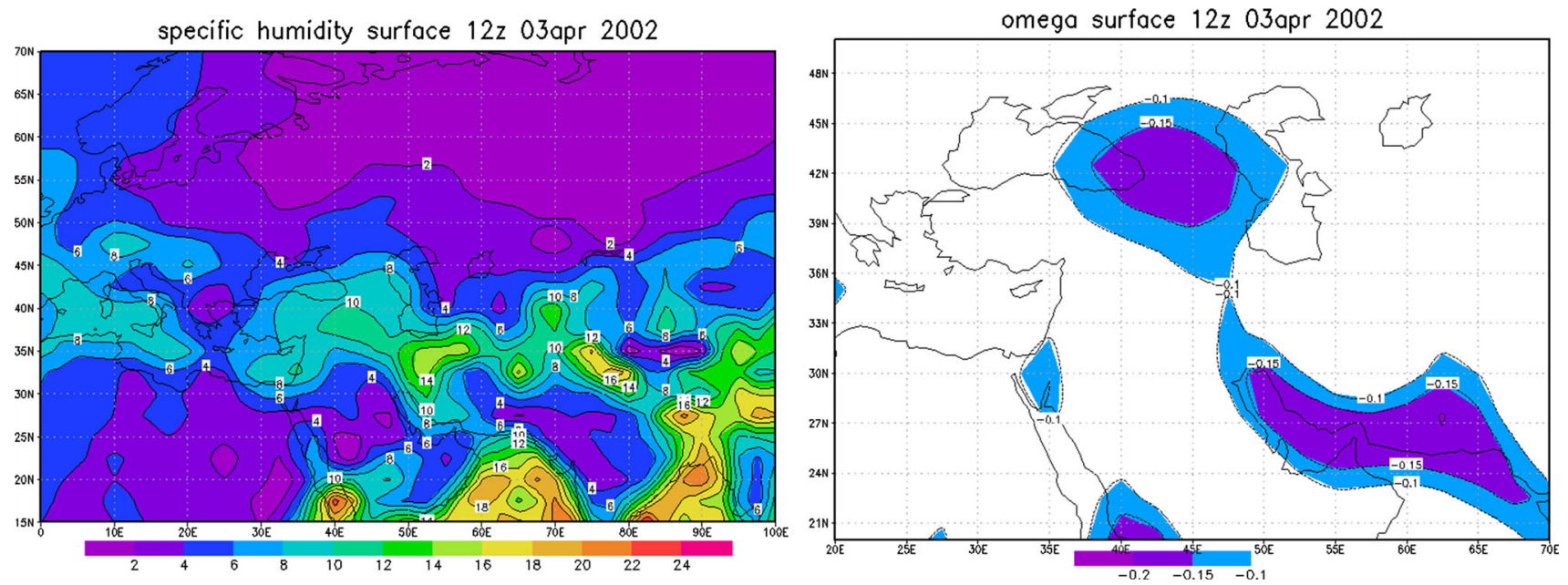

Figure 24. Specific humidity and omega at $500 \mathrm{mb}$ geopotential height for 3 April, 2002.

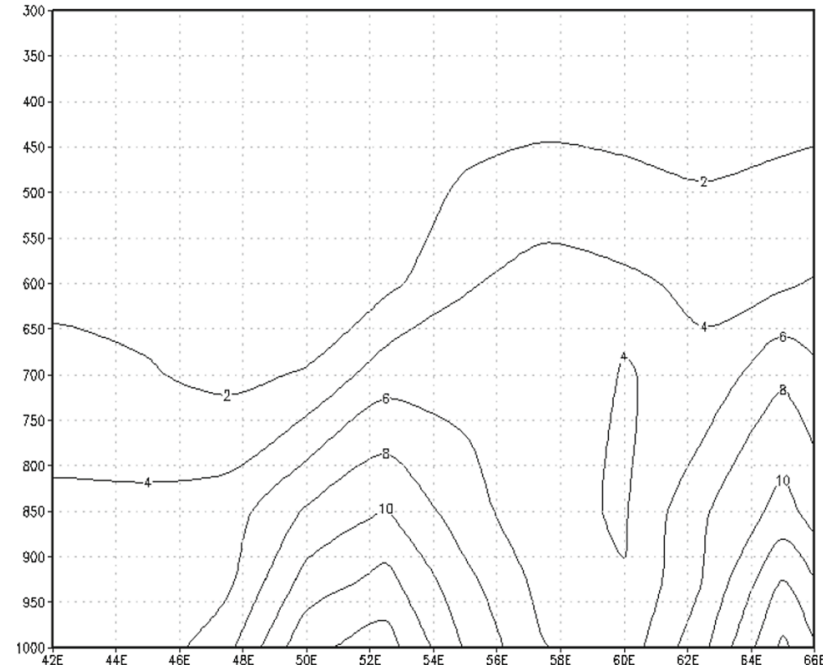

Figure 25. Pattern 3, sixth kind of Hovmoller graph.

To investigate the omega and specific humidity, maps of February 21 in 2009 were used (figure 21). Two negative omega cores can be seen in the western half of Iran and in the Black Sea which refers to the upward movements in the atmosphere. Specific humidity map indicates that 8-10 grams of humidity in the western half of Iran has provided the conditions for atmospheric precipitation. Hovmoller graph (figure 22) also indicates the concentration of humidity in the study area. On the whole, the stated factors provided the required conditions for the occurrence of thunderstorms and hail incidence.

\subsection{Pattern 3: Analysis of sea level pressure}

In the third pattern (figure 23), a low pressure system established in the east of Iran. Also, a high pressure tongue with central core pressure of 1013

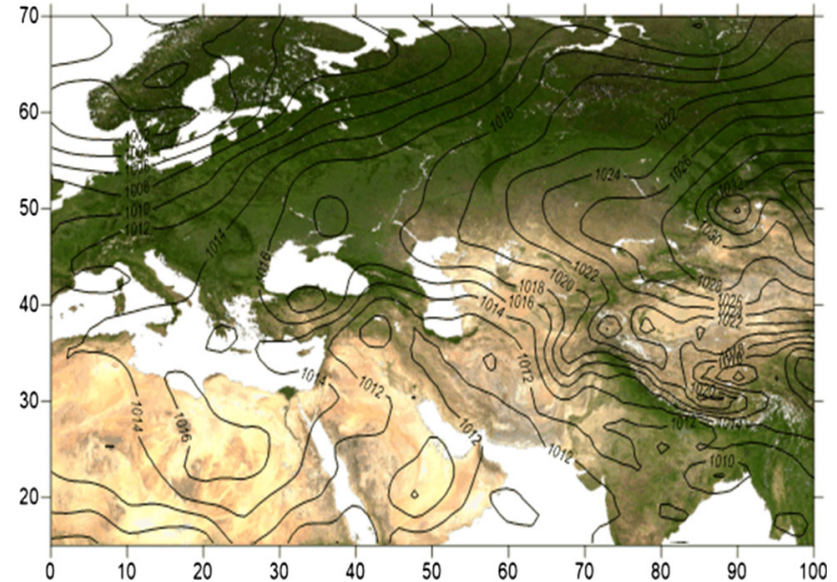

Figure 26. Pattern 3, sea level pressure.

mb was transmitted from the respective area. A high-pressure center in the northeast of Africa and two relatively high pressure centers settled in the south of Italy and east of Europe. A strong thermal high pressure formed in Siberia and its tongue has affected the northern parts of the Caspian Sea. The existence of different pressure systems around the study area has caused the instability of air conditions. Transmission of cold weather from the east and northeast of Siberia and transmission of settled hot weather in the northeast of Africa towards central parts of Iran has caused atmospheric instability leading to the ascendance of air and precipitations such as hail.

Investigating the omega map (figure 24), on this day, shows two negative core omegas, one of which can be seen in the Persian Gulf and the other in the northwest of Iran. Severe gradient of pressure created through settled pressure pattern at sea level provided the conditions for the ascendance of air and made the atmosphere of Iran 

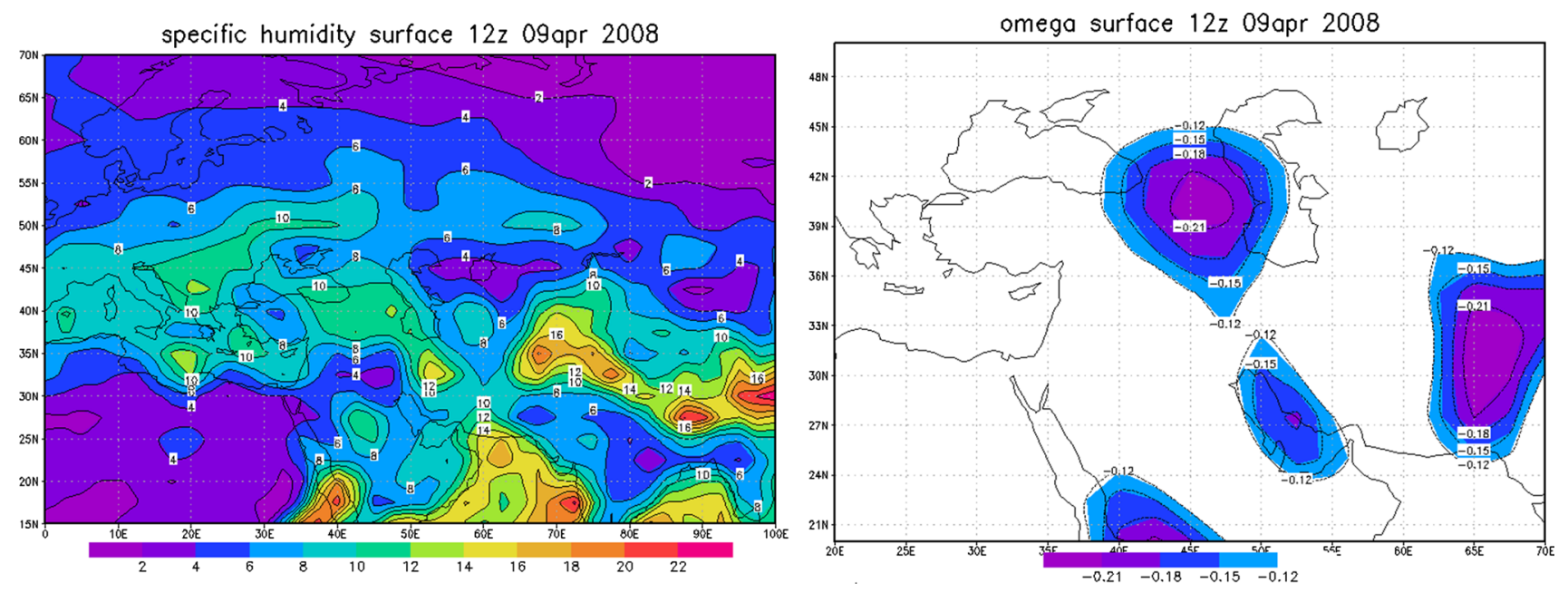

Figure 27. Specific humidity and omega at $500 \mathrm{mb}$ geopotential height for 9 April, 2008.

unstable. Investigating the specific humidity map in the study area shows that specific humidity reached $16 \mathrm{~g} / \mathrm{kg}$ and regarding the sea level pressure pattern and created gradient, it can be said that humidity of this region at this atmospheric level mostly has been provided from the Mediterranean Sea. Hovmoller graph (figure 25) shows that there is maximum humidity in the study area and it continued up to $750 \mathrm{mb}$ level. These weather conditions led to a severe air ascendance and hail occurrence.

\subsection{Pattern 4: Analysis of sea level pressure}

In the fourth pattern, a relatively low-pressure system with a central pressure of $1010 \mathrm{mb}$ settled in the south of Saudi Arabia and its tongues affected the west of Iran (figure 26). On the other hand, a strong high-pressure system formed in Siberia. Another high-pressure system can be seen in the northeast of Africa in contrast with low-pressure system of Saudi Arabia. According to the mentioned pressure systems, extreme pressure gradient established between the low and high pressure systems influenced Iran.

Investigating the position of omega in the atmosphere, on this day, demonstrates the severe instability over the study area (figure 27). Two cores of negative omega formed in the northwest and southwest of Iran indicate its atmospheric instability and intense vertical motions. Specific humidity map at $1000 \mathrm{mb}$ level shows that the amount of specific humidity is high. This amount of humidity can aid the aggravation of upward movements on the ground and has provided the

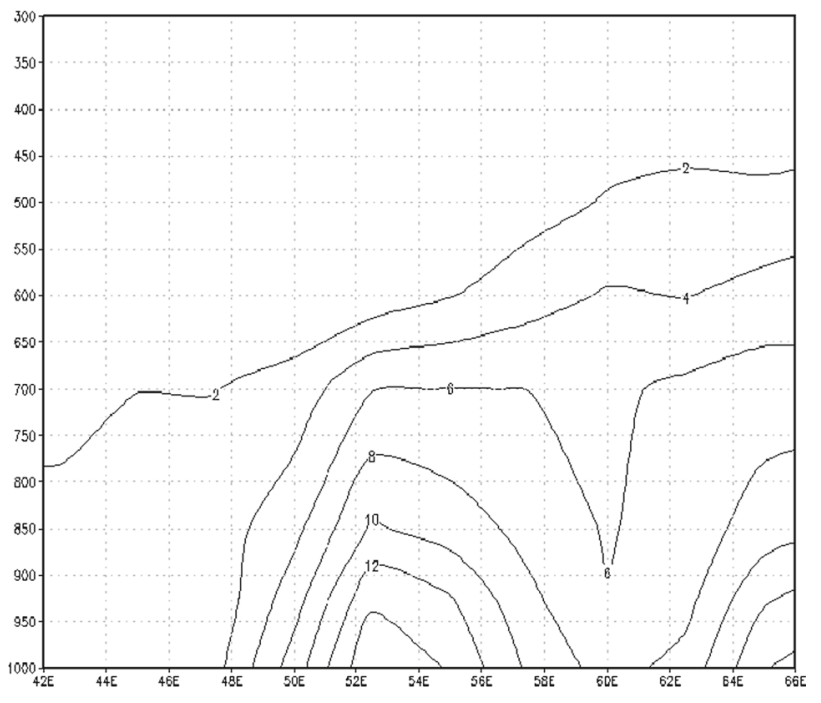

Figure 28. Pattern 3, sixth kind of Hovmoller graph.

necessary humidity for the occurrence of thunderstorm along with hail. Hovmoller graph (figure 28) also refers to the accumulation of humidity at $800 \mathrm{mb}$ level in the study area. The mentioned conditions have caused the formation of hail in Chaharmahal and Bakhtiari province.

\section{Conclusions}

The results of this study revealed that the highest amount of hail occurrence in Chaharmahal and Bakhtiari province can be seen in the mountainous areas of Koohrang. This finding is consistent with the results of a previous study by Michaelides et al. (2008) and Lashkari et al. (2015), which indicated that hail occurrence is more probable in the mountainous areas of Cyprus and Iran compared to the plains. In the study area, the 
peak of hail occurrence can be observed in spring. According to the results of clustering, four patterns that lead to hail occurrence at $500 \mathrm{mb}$ geopotential height and four patterns above sea level pressure were detected. Geopotential height patterns at $500 \mathrm{mb}$ level included cut-off low over Turkey, formation of cut-off low over eastern Europe, creation of cut-off low in Europe, and a low trough in the west of the Mediterranean Sea. By creating trough and transmission of cold weather from higher latitudes towards lower latitudes and making instability, these patterns led to the formation of hail in the study region.

Sea level pressure patterns that lead to hail occurrence in the respective area also included four patterns: (1) formation of high-pressure systems over the eastern Europe and west of China, and formation of low-pressure systems over Russia and central Iran; (2) establishment of high-pressure system over Iran, Egypt and west of China and the existence of low-pressure system over northern Europe; (3) establishment of pressure systems on the east of Iran and the study area, and formation of high-pressure systems over the northeast of Africa and Siberia; and (4) establishment of a highpressure system over Siberia, west of China and northeast of Africa, and a relatively low pressure system over the Saudi Arabia. The establishment of these systems leads to the intensification of convergence flows and air instability on the earth's surface and ascend of humid air to the upper layers of the atmosphere. According to the identification of synoptic patterns leading to hail in Chaharmahal and Bakhtiari province, it is better that environmental planners offer solutions to mitigate the damages.

\section{Acknowledgements}

The authors would like to thank Dr Vali Mohammadi, University of Mohaghegh Ardabili, Ardabil, Iran, for his kind and valuable help in preparing the manuscript.

\section{References}

Allen J T and Karoly D J 2014 A climatology of Australian severe thunderstorm environments 1979-2011: Inter-annual variability and ENSO influence; Int. J. Climatol. 34 81-97.
Aran M, Pena J and Tora A 2011 Atmospheric circulation patterns associated with hail events in Lleida (Catalonia); Atmos. Res. 100 428-438.

Beck C, Philipp A, Demuzere M, Ustrnul Z, Cahynova M and Tveito O E 2008 Classifications of atmospheric circulation patterns; Ann. N.Y. Acad. Sci. 1146 105-152.

Brooks H E, Lee J W and Craven J P 2003 The spatial distribution of severe thunderstorms and tornado environments from global reanalysis data; Atmos. Res. 67-68 73-94.

Buckley B W, Leslie L M and Wang Y 2003 The Sydney hailstorm of April 14, 1999: Synoptic description and numerical simulation; Meteorol. Atmos. Phys. 76 167-182.

Chantraket P, Kirtsaeng S, Detyothin S, Nakburee A and Mongkala A 2015 Characteristics of hailstorm over northern Thailand during summer season; Environ. Asia 8(1) 101-114.

Cica R, Burcea S and Bojariu R 2015 Assessment of severe hailstorms and hail risk using weather radar data; Meteorol. Appl. 22(4) 746-753.

Evan A, Kalina E A, Friedrich K, Brian C, Motta B C, Deierling W, Stano G T and Rydell N N 2016 Colorado plowable hailstorms: Synoptic weather, radar, and lightning characteristics; Wea. Forecast. 31(2) 663-693.

Garcia-Ortega E, Fita L, Romero R, Lopez L, Ramis C and Sanchez J L 2007 Numerical simulation and sensitivity study of a severe hailstorm in northeast Spain; Atmos. Res. 83 225-241.

Giaiotti D, Nordio S and Stel F 2003 The climatology of hail in the plain of Fruili Venezia Giulia; Atmos. Res. 67-68 $247-259$.

Hervada-Salaa C and Jarauta-Bragulat E 2004 A program to perform Ward's clustering method on several regionalized variables; Comput. Geosci. 30 881-886.

Johnson A W and Sugden K E 2014 Evaluation of sounding derived thermodynamic and wind-related parameters associated with large hail events; EJSSM 9(5) 1-42.

Kunz M and Puskeiler M 2010 High-resolution assessment of the hail hazard over complex terrain from radar and insurance data; Meteorol. Z. 10 427-439.

Kunz M, Sander J and Kottmeier C 2009 Recent trends of thunderstorm and hailstorm frequency and their relation to atmospheric characteristics in southwest Germany; Int. J. Climatol. 29 2283-2297.

Lashkari H, Pazhouh F and Beitar M 2015 Synoptic analysis of pervasive hail precipitation in the west of Iran; Geogr. Space (Iran) 15(50) 83-105.

Li M, Zhang Q and Zhang F 2016 Hail day frequency trends and associated atmospheric circulation patterns, over China during 1960-2012; J. Climate 29 7027-7044.

Merino A, Wu X, Gascon E, Berthet C, Garca-Ortega E and Dessens J 2014 Hailstorms in southwestern France: Incidence and atmospheric characterization; Atmos. Res. 140-141 61-75.

Merino A, Garcia-Ortega E, Lopez L, Sanchez J L and Guerrero-Higueras A M 2013 Synoptic environment, mesoscale configurations and forecast parameters for hailstorms in southwestern Europe; Atmos. Res. 122 183198.

Michaelides S C, Savvidou K, Nicolaides K A, Orphanou A, Photiou G and Kannaouros C 2008 Synoptic, thermodynamic and agro economic aspects of severe hail events in Cyprus; Nat. Hazards Earth Syst. Sci. 8 461-471. 
Mohr S and Kunz M 2013 Trend analysis of convective indices relevant for hail events in Germany and central Europe; Atmos. Res. 123 211-228.

Mohr S, Kunz M and Geyer B 2015 Hail potential in Europe based on a regional climate model hindcast; Geophys. Res. Lett. 42 10,904-10,912.

Nisi L, Martius O, Hering A, Kunz M and Germann U 2016 Spatial and temporal distribution of hailstorms in the Alpine region: A long-term, high resolution, radar-based analysis; Quart. J. Roy. Meteor. Soc. 142(697) 15901604.

Philipp A and Bartholy J 2010 COST733CAT-A database of weather and circulation type classifications; Phys. Chem. Earth. 35 360-373.

Saa Requejo A, Garcia Moreno R, Diaz Alvarez M C, Burgaz F and Tarquis M 2011 Analysis of hail damages and temperature series for peninsular Spain; Nat. Hazards Earth Syst. 11 3415-3422.

Corresponding editor: SURESH BABU
Schemm S, Nisi L, Martinov A, Leuenberger D and Martius O 2016 On the link between cold fronts and hail in Switzerland; Atmos. Sci. Lett. 17(5) 315-325.

Simeonov P and Giorgiev C G 2003 Severe wind/hail storms over Bulgaria in 1999-2001 period: Synoptic- and Meso-scale factors for generation; Atmos. Res. 67-68 629-643.

Sioutas M V and Flocas H A 2003 Hailstorms in northern Greece: Synoptic patterns and thermodynamic environment; Theor. Appl. Climatol. 75 189-202.

Twardosz R 2010 A synoptic analysis of the diurnal cycle of thunderstorm precipitation in Krak'ow (southern Poland); Int. J. Climatol. 30 1008-1013.

Vinet F 2001 Climatology of hail in France; Atmos. Res. 56 309-323.

Wapler K and James P 2014 Thunderstorm occurrence and characteristics in central Europe under different synoptic conditions; Atmos. Res. 158 1-14. 